\title{
Strata Sosial Gelar Adat Suku Bugis Pattinjo di Kalimantan Utara (Kajian Sosiolinguistik)
}

\author{
Muhammad Ilham \\ Fakultas Keguruan dan Ilmu Pendidikan, Universitas Borneo Tarakan \\ ilhammuhammad@borneo.ac.id \\ Ady Saputra \\ Fakultas Keguruan dan Ilmu Pendidikan, Universitas Borneo Tarakan \\ adysaputra.ppsunm@gmail.com \\ Iva Ani Wijiati \\ Fakultas Keguruan dan Ilmu Pendidikan, Universitas Borneo Tarakan \\ wijiatiivaani@borneo.ac.id
}

Received: 13 August 2021; Revised: 02 October 2021; Accepted: 14 December 2021 DOI: http://dx.doi.org/10.37905/aksara.8.1.195-200.2022

\begin{abstract}
Abstrak
Penelitian ini bertujuan untuk mengetahaui strata sosial gelar gelar adat suku Bugis Pattinjo yang ada di Kalimantan Utara. Hal ini dilakukan agar gelar adat tersebut tidak sembarang digunakan oleh orang lain. Penelitian ini menggunakan enelitian Kualitatif. Fokus penelitian ini ke strata sosial gelar adat suku Bugis Pattinjo di Kalimantan Utara. Teknik pengumpulan data dalam penelitian ini menggunakan teknik wawancara mendalam, observasi, dan dokumentasi. Hasil penelitian yang didapatkan dalam penelitian ini (1) Raja (2) Puang (3) Arung (4) Daen (5) Andi (6) Iye (7) Kaunan (8) Ua (9) Pua (10) Ambe (11) Indo. Fungsi pemberian gelar adaT suku Bugis Pattinjo merupakan suatu perbedaan status dalam masyarakat adat yang diturunkan secara turun-temurun.
\end{abstract}

Kata Kunci: strata sosial, adat, suku, sosiolinguisitik.

\section{PENDAHULUAN}

Suku Bugis kental dengan adat dan istiadatnya, sehingga menjadikannya punya ciri khas dengan suku-suku lainnya. Suku Bugis kental dengan gelar-gelar bangsawan yang diberikan kepada orang-orang, berdasarkan tingkat strata sosialnya di dalam masyarakat. Gelar-gelar tersebut tidak sembarang diberikan kepada masyarakat, harus memperhatikan betul silsilah keturunannya. Walaupun demikian, bukan berarti melihat kaya tidaknya seseorang, berkelas atau masyarakat biasa, tetapi benar-benar melihat bagaimana silsilah keturunannya, apakah bersifat baik atau buruk untuk bisa menduduki gelar-gelar bangsawan.

Kebudayaan suku Bugis memang sangat kental dan menjadi kebutuhan dalam masyarakat tersebut. Adat dan istiadat adalah sesuatu yang sakral dalam kehidupan suku Bugis, sehingga jika terjadi pelanggaran maka ada sangsi yang diberikan. Maka, perlu pemangku adat yang jujur, dermawan, tidak memihak, dan bertanggung jawab. Gelar bangsawan teringgi suku Bugis adalah Raja, dengn susunan strukturnya Puang, Arung, , Daen, Andi, Iye, Kaunan, Ua, Pua, Indo, Ambe. Gelar tersebut sebagi penanda bagaiamana starata sosial orang tersebut

Gelar-gelar tersebut menjadi hal yang saklar dan sangat sensitif dalam masyarakat Bugis dan seiring perkembangan zaman seolah gelar-gelar tersebut tidak memperhatikan strukturnya. Lebih menilai ke sisi kekayaan semata, seolah bergeser ke "siapa yang lebih kaya itu yang dapat" maka, masalah tersebut perlu untuk dikaji agar gelar tersebut tidak melanggar aturan adat. 
Berdasarkan latar belakang tersebut maka, penulis tertarik meneliti struktur gelar kebangsawanan sebagai tanda bagaiamana struktur sosial dalama masyarakat. Tujuan penulis meneliti gelar kebangsawanan dengan harapan gelar kebangsawanan tidak melanggar aturan adat istiadat kebangsawanan suku Bugis.

Adapun tujuan pada penelitian ini adalah mendeskripsikan sistem pemberian gelar kebangsawanan suku bugis Pattinjo di Tarakan Kalimantan Utara.

Target luaran yang diharapkan pada penelitian ini adalah untuk lebih memahami gelar-gelar kebangsawanan yang terdapat pada masyarakat Bugis Pattinjo khususnya yang ada di kota Tarakan.

\section{METODE PENELITIAN}

Penelitian ini termasuk penelitian lapangan. Penelitian ini merupakan penelitian kualitatif model etnografi, pengumpulan Data dilakukan dengan natural setting (kondisi alamiah). Pendekatan etnografi digunakan untuk menjelaskan potensialitas sistem gelar kebangsawanan dan aktualisasinya di masyarakat pemiliknya.

Teknik pengumpulan data dalam penelitian ini adalah teknik observasi (participant observation), rekam, wawancara mendalam dan catat. Hal ini sesuai pendapat Sudikan (2001:173), teknik pengumpulan data pada sastra lisan dapat menggunakan (1) observasi, (2) perekaman, (3) wawancara, dan (4) pencatatan. Dengan teknik-teknik tersebut diharapkan dapat memperoleh data yang lebih akurat sesuai fokus penelitian. Teknik-teknik tersebut juga dapat dilakukan peneliti secara bersamaan dengan menyesuaikan kondisi di lapangan.

Dalam teknik observasi akan dilibatkan tiga objek sekaligus yaitu lokasi tempat penelitian berlangsung, para pelaku dengan peran tertentu, dan aktivitas para pelaku yang dijadikan sebagai objek penelitian (Ratna, 2010:220). Melalui observasi alamiah dan wawancara mendalam, data yang terkumpul akan semakin lengkap. Data yang diperoleh dari pengamatan dan wawancara secara alamiah akan lebih bermakna.

Untuk melengkapi kegiatan observasi dan wawancara, peneliti melakukan perekaman dan pencatatan di lapangan. Perekaman dengan menggunakan kamera video ataupun tape recoder bertujuan untuk merekam proses wawancara yang dilakukan oleh peneliti dan informan serta untuk merekam percakapan. Hasil rekaman tersebut selanjutnya akan ditranskripsi dan diterjemahkan ke dalam bahasa Indonesia dengan melakukan pemaknaan. hal ini dilakukan untuk mendalami data yang di dapat melalui wawancara. Sementara catatan lapangan digunakan untuk mencatat bagian yang penting dari observasi dan wawancara yang dilakukan peneliti.

Informan adalah pembicara asli, yang natural untuk berbicara dalam bahasanya atau dialek yang digunakan dalam kehidupan bermasyarakat. Informan dibutuhkan untuk mencari informasi mengenai sistem pemberian gelar kebangsawanan suku Bugis. Penentuan informan, dalam penelitian gelar kebangsawanan penting dilakukan. Hal tersebut mengingat tidak semua suku Bugis memahami, mengetahui, serta mampu menerjemahkan pemberian gelar kebangsawanan tersebut

Pada penelitian ini, informan yang dipilih berdasarkan beberapa pertimbangan, yaitu (1) penduduk asli (suku Bugis asli), (2) dewasa dari segi usia, (3) memliki pengetahuan yang baik mengenai sistem pemberian gelar kebangsawanan suku Bugis terutama seorang pewaris dalam gelar kebangsawanan, (4) sehat jasmani dan rohani, (5) 
Tokoh masyarakat, (6) Memiliki informasi lain yang diperlukan untuk menjawab fokus penelitian.

Teknik transkripsi yang digunakan dalam penelitian ini mengikuti petunjuk Hutomo (1991:5-6) melalui tahapan sebagai berikut: (1) transkripsi secara kasar, artinya semua simbol-simbol berupa gelar yang ada di dalam gelar kebangsawanan dalam rekaman dipindahkan ke tulisan tanpa mengindahkan tanda baca; (2) transkripsi kasar tersebut disempurnakan, dengan mencocokkan kembali data lisan dengan data tulis; (3) setelah transkripsi disempurnakan, selanjutnya peneliti memulai menekuni hasil transkripsinya. Kata-kata dan kalimat yang kurang jelas diberi tanda baca dan dan tandatanda lain yang diperlukan; dan (4) Setelah hasil transkripsi diberi tanda-tanda baca dan perwajahan (bentuk) yang sempurna, selanjutnya diketik komputer. Tahap ini dan tahaptahap sebelumnya dilakukan secara berulang-ulang dengan dikoreksi kembali.

Analisis data dalam penelitian ini dilakukan dengan teknik kualitatif etnografi dengn memahami gelar kebangsawanan yang ada di suku Bugis, mulai dari proses pengumpulan data sampai dengan data terkumpul seluruhnya. Analisis data dengan kualitatif etnografi yang dimaksudkan untuk mendeskripsikan sistem budaya khususnya dalam pemberian gelar kebangsawanan suku Bugis di Kalimantan Utara. Langkahlangkah analisis data dalam penelitian ini, yaitu mengumpulkan data penelitian yang telah ditranskripsikan, diterjemahkan, dan diidentifikasikan sesuai fokus penelitian (data dalam sistem pemberian gelar kebangsawanan suku Bugis yang ada di Tarakan Kalimantan Utara).

\section{HASIL PENELITIAN DAN PEMBAHASAN \\ Data 1 Raja}

Iya tu to gelar Raja, iya banggo puang. Mangapia nadikua raja sa iya tanni tahta pamerintahan adat. Tapi, iyato bisa ditanang Raja katurunan Puangpa Terjemahan: namarege too sipa'na, bisai jadi panutan.

Seseorang yang mendapatkan gelar Raja, pada dasarnya Ia pula yang disebut dengan sebutan Puang. Mengapa dikatakan Puang karena dialah satu-satunya memegang pemerintahan adat. Tetapi sesungguhnya yang bisa dijadikan raja adalah keturunan Puang yang mempunyai sifat yang baik yang bisa jadi panutan

Raja merupakan tahta tertinggi dalam adat bugis Pattinjo di Tarakan, raja yang memegang kendali mengenai aturan dan hukum yang berlaku dalam adat. Walapun sesungguhnya raja merukan gelar turunan dari Puang. sehingga masyarakat perlu pahamai bahwa yang berhak menjadi raja bukan ditentukan dari banyak harta, tetapi dilihat dari asal usul keluarga dan perilaku yang baik.

\section{Data 2 Puang}

Iya tuu gelar Puang, berarti tahta paling matande selain raja, taen daonanna kedikitai tahta adat. Polena tee Puang waktu tempo jolo sibuno buno kanai to tau. Iamo sa sibuno-buno kanai to tau na tiba-tiba denno tau ratu memppanganga kua dau sibuno-buno. iamo nassabai na amang. Nadijadikanramo puang tedio tau mappangaja. Tapi sebenarnya njoo ikussen kua mboo nanei pole taunna. Talluka sibawa pitoka sitindro. macoai yolo kakai mundri. 
Gelar Puang tersebut adalah tahta paling tertinggi sebelum ada keduduka raja di dalam adat. Sebenarnya sejarah Puang berasal dari sekelompok masyarakt yang saling membunuh. Dari peristiwa tersebut muncullah seseorang yang menjadi penengah mengenai pertikaian tersebut. Namun, tidak seorang pun yang tahu mengenai asal-muasal munculnya orang tersebut. Orang tersebut hanya mengatakan saya bersama tiga orang, namun sebenarnya secara keseluruhan ada tujuh orang. Yang paling muda di depan dan yang paling tua di belakang.

Berdasarkan data tersebut maka dapat dilihat bahwa puang merupakan tahta tertinggi selain raja. Hal ini dapat diketahui bahwa yang berhak menjadi raja adalah keturuan puang. sehingga sudah pasti yang berhak menjadi raja adalah keturuan yang mempunyai Tahta Puang. maka perlu diketahaui bahwa ketika menjadi raja maka ada dua tahta yang dipegang yakni raja dan puang.

\section{Data 3 Arung}

Iyatuu to arung berarti iyato tannni bunga kelalan pemerintahan berarti mempunyai jabatan kerajaan. Tapi wading batoi diodi puang. Sa bisa Terjemahan: manjadi arung ke keturunan Puang.

seseorang yang memegang gelar arung, maka orang tersebutlah yang memegang jabatan dalam pemerintahan adat, yakni jabatan kerajaan. Namun, orang tersebut juga bisa dipanggil dengan sebutan Puang. Karena yang bisa menjadi arung adalah keluarga Puang juga.

Arung sebutan lain dari Raja,sehingga pada dasarnya Raja dan Arung sama saja. Arung dan Raja sama bersala dari keturunan puang.

\section{Data 4 Andi}

Iatuu to Andi, iyamo tuи katurunan puang too. Tapi tombedakanni dengan Puang dan Arung sa pendidikanna sekolana.

Terjemahan:

pada dasarnya gelar Andi juga merupakan keturunan Puang, tetapi yang mebedakan adalah pendidikan.

Berdasarkan data tersebut dapat diketahui bahwa gelar Andi merupakan gelar kebangsaanan dari seseorang yang mempunyai gelar keturunan Puang dan berpendidikan tinggi.

\section{Data 5 Daen}

Pada-pada pajujung bunga nene tumane sola nene tubenena majujung bunga adat manan. Taen campurui kapuanganna. Iyato nodi daenni ananga kanara wading. Njoo kesembarang diodi daen, kecuali to majujung bunga manan

Terjemahan: pajajianna.

Nenek atau kakek sama-sama mempunyai jabatan dalam pemerintahan adat. Murni keluraga Puang tanpa ada campuran lain. Yang berhak memanggil dengan sebutan Daen hanya anaknya dan orang yang kedua orang tuanya memunyai jabatan adat. tidak boleh sembarang orang memanggil sebutan Daen. 
Berdasarkan data tersebut dapat diketahui bahwa panggilan Daen hanya berhak disandang oleh oranng yang mempunyai kakek dan nenek atau ibu dan ayah mempunyai jabatan adat

\section{Data 6 Iye} Terjemahan:

Iyato diodi Iyye tuu, berarti denno bija kapaunganna, tapi mbae sabalirai.

Seseorang yang dipanggil dengan sebutan Iye, berarti menandakan bahwa orang tersebut merupakan keturunan puang, walaupun hanya salah satu dari nenek moyangnya.

Data tersebut menunjukkan bahwa seseorang yang dipanggil Iye adalah seseorang yang punya keturuan yang bergelar Raja, namun hanya salah satu dari orang tua atau nenek moyangnya.

\section{Data 7 Kaunan}

Iyato kaunan mompoi sa denno pelanggaran nakabua pabunorakai, mabokorakai, atau denno indanna nanabajaranni Puang Indanna iyamo tuu kaunan mana, sanakannai aturan adat. Pokona seluruh pelannggaran battoa jadi kaunan manani tuu.

Berdasarkan data tersebut dapat diketahui bahwa sesungguhnya gelar kaunan sama dengan hamba sahaya di zaman nabi. Namun perbdaanya adalah yang menjadi kaunan dalam aturan adat bugis Pattinjo adalah seseorang yang melakukan pelanggaran besar, seperti memerkosa, membunuh, mencuri, atau mempunyai utang kepada orang lain namun yang membayarkan adalah raja maka secara aturan adat orang tersebut menjadi kaunan

Terjemahan:

Kaunan muncul karena adanya pelanggaran adat yang telah diperbuat, entah membunuh, mencuri, memerkosa, atau seseorang punya utang kepada orang lain namun yang melunasi utangnya adalah Puang makan orang tersebut secara aturan adat akan menjadi kaunan. Perlu ketahui, seluruh pelanggaran

Data $8 \mathrm{Ua}$ besar yang melanggar aturan adat maka akan menjadi kaunan

Ua tu, istilah nakabua-buara tau, njo kejelassi sejarahna. Ua pole pua-pua dede. Pabellena to tumatua sola ananga

Terjemahan:

istilah Ua tidak mempunyai sejarah yang berarti, hanya istilah yang dibuatbuat oleh seseorang. Ua pole pua-pua dede. Pabellena sola ananga.

Data tersebut menujukkan panggilan Ua tidak berkaitan dengan gelar kebangsawanan. Istilah Pua berasal dari permainan anatara anak dengan orang tua dalam suku Bugis, yakni seorang anak yang ditaruh di betis lalu diangkat naik turun menggunakan betis, itulah dinamakan pua-pua dede

\section{Data 9 Pua}

Pua, taen too sejarahna, istilah kanara nakabua to tau

Terjemahan:

Begitupun denga panggilan Pua, tidak mempunyai sejarah yang berarti, hanya istilah yang dibuat-buat oleh seseorang

Pada dasarnya panggilan Pua sama halnya dengan Ua. Tidak ada keterkaitan dengan gelar kebangsawanan. 


\section{Data 10 ambe}

To tau pajajian, ambe ureraka, atatu salebi matuai tau naikita, wading too sataen lalo katurunan puangga iyamo nadiodi ambe

Terjemahan:

Entah orang tua kandung, paman, atau seseorang yang lebih tua dari kita, semua itu boleh dipanggil dengan sebutan Ambe. Salah satu sebab juga

Data 11 Indo. dipanggil Ambe karena orang tersebut tidak mempunyai keturunan Puang

Indo sanajajiakki, indo sana lebih matui naikita, indo ureraka, wading tto sataen lalo katuruan puangga iyamo nadiodi Indo.

Terjemahan:

Indo karena telah melahirkan kita ke dunia, Indo karena lebih tua dari diri kita, Salah satu sebab juga dipanggil Ambe karena orang tersebut tidak mempunyai keturunan Puang

Berdasarkan data tersebut panggilan Indo adalah panggilan yang pada dasarnya berlaku kepada semua ibu di suku bugis, bukan melihat gelar kebangsawanan. Meskipun kebanyakan orang tua dipanggil Indo karena tidak mempunyai keturuan gelar kebangsawanan.

\section{KESIMPULAN}

1. Berdasarkan hasil penelitian ditemukan sebelas data yang berkaitan dengan gelar adat yang ada pada suku Bugis Pattinjo Kalimantan Utara, di antaranya (1) Raja (2) Puang (3) Arung (4) Daen (5) Andi (6) Iye (7) Kaunan (8) Ua (9) Pua (10) Ambe (11) Indo.

2. Berdasarkan data tersebut maka diketahui, bahwa yang berhak menjadi Raja, Arung, Daen, Andi, dan Iyee adalah seseorang yang mempunyai keturunan yang mempunyai gelar adat Puang.

3. Gelar adat yang paling rendah adalah gelar kaunan yng diberikan kepada seseorang karena melakukan pelanggaran besar sehingga keturunanya tidak berhak mendapatkan gelar Puang atau gelar kebangsawanan

\section{REFERENSI}

Baihaq, Sarah Fadhilah. 2017. Pewarisan Nilai Budaya Melalui Simbol Gelar Adat Lampungbuay Nunyai.

Djausal, Anshori \& dkk. 2002. "Masyarakat Adat Marga Bunga Mayang Sungkai”.

Kotabumi: Masyarakat Adat Marga Bunga Mayang Sungkai.

Nurani, Rahmanisya Okti. 2016. Cakak Pepadun; Upacara Pemberian Gelar Untuk Adat

Pepadun. Malahayati. Ac. Id By

Miles, B Matthew dan Huberman, Michael A. 1992. Analisis Data Kualitatif. Jakarta: Penerbit Universitas Indonesia.

Moleong, Lexy J. 2011. Metodologi Penelitian Kualitatif. Bandung: PT Remaja Rosdakarya 